\title{
IDENTIFICATION OF BLEACHED AND POLYMER-IMPREGNATED JADEITE
}

\author{
By Emmanuel Fritsch, Shun-Tien Ten Wu, Thomas Moses, Shane F. McClure, and Mike Moon
}

The "bleaching" treatment of jadeite jade has become prevalent in higher- as well as lowerquality material. "Bleaching" is actually a two-step process whereby a brown or gray color component (probably iron compounds filling the fractures) is removed chemically, followed by impregnation of the resulting white to green material with some type of polymer. The treatment product is commonly referred to as "bleached jadeite" or " $B$ jade" in the Orient. Although several gemological tests are useful in detecting this treatment, infrared spectroscopy is the only method found thus far that provides conclusive evidence of polymer impregnation in all cases.

\section{ABOUT THE AUTHORS}

Dr. Fritsch is manager of the Research Department, Gemological Institute of America, Santa Monica, California; Mr. Shun-Tien Ten Wu is director of International Gem Inc., Kaohsiung, Taiwan; Mr. Moses is director of identification at the GIA Gem Trade Laboratory, Inc., New York; Mr. McClure is supervisor of identification at the GIA Gem Trade Laboratory, Inc., Santa Monica; and Mr. Moon is a research associate at GIA, Santa Monica.

Acknowledgments: The authors thank the following for information and/or samples: Don Kay of Mason and Kay, C. J. Ko of On Tai Jade and Travel, John Ng of Jade N' Gem, Frankie Ho, June Hanano Yurkiewicz of Evan Caplan Inc., and GIA's Philip Yurkiewicz, Eddie Decsi, C. M. Ou Yang, Dominic Mok, and James Shigley. Sam Muhimeister, Patricia Maddison, Karin Hunwit, Dave Hargett, Bob Kammerling, Bob Crowningshield, and Chris Smith helped with testing. Ed Garland of Nicolet Instruments helped identify the polymer.

Gems \& Gemology, Vol. 28, No. 3, pp. 176-187

CC 1992 Gemological Institute of America

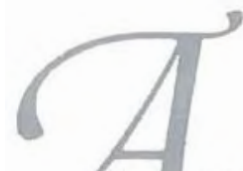

new type of jadeite treatment, often referred to in the trade as "bleaching," has become prominent in the $1990 \mathrm{~s}$ (figure 1). It is seen worldwide, but particularly in Taiwan, Hong Kong, and Japan. The appearance of this treatment prompted several reports in the trade press. Of special concern was the fact that the treatment initially went undetected by some gemological laboratories; this reportedly led to a $50 \%$ decrease in jadeite sales in Japan over a three-month period ("Green jadeite bleached then dyed emerald green," 1991; "New filler threatens jadeite sales in Japan," 1991).

The process reportedly consists of two steps-first bleaching and then polymer impregnation. The bleaching enhances the appearance of the jadeite primarily by removing a brown component from the gem's overall color. The polymer impregnation fills any voids left by the bleaching, thus enhancing the clarity appearance of the stone and stabilizing it. The change produced by this two-part treatment may be relatively minor or quite significant (figure 2); the material that results is called "grade B jade" or simply "B jade" by many dealers in the Orient. So far, this treatment has been reported only for green and white jadeite (not for other colors of jadeite, such as "lavender," or for nephrite jade). However, it has been identified in all qualities of jadeite, as dealers seek to improve the appearance (and, therefore, the salability) of even the finer materials (see figure 3).

The expression bleached jadeite is misleading because it refers only to the first half of this two-step treatment process. In this article, we will use the word bleached alone to mean that the piece of jadeite has only been bleached. If the piece has also been impregnated, we will indicate so and identify the impregnation material-typically some type of polymer, such as a wax or a resin. In accordance with the practice in Hong Kong and Taiwan, we will occasionally refer to the process by which jadeite is both bleached and polymer impregnated as "bleaching" treatment. Note, however, that jade that has only been bleached rarely appears on the market because the 


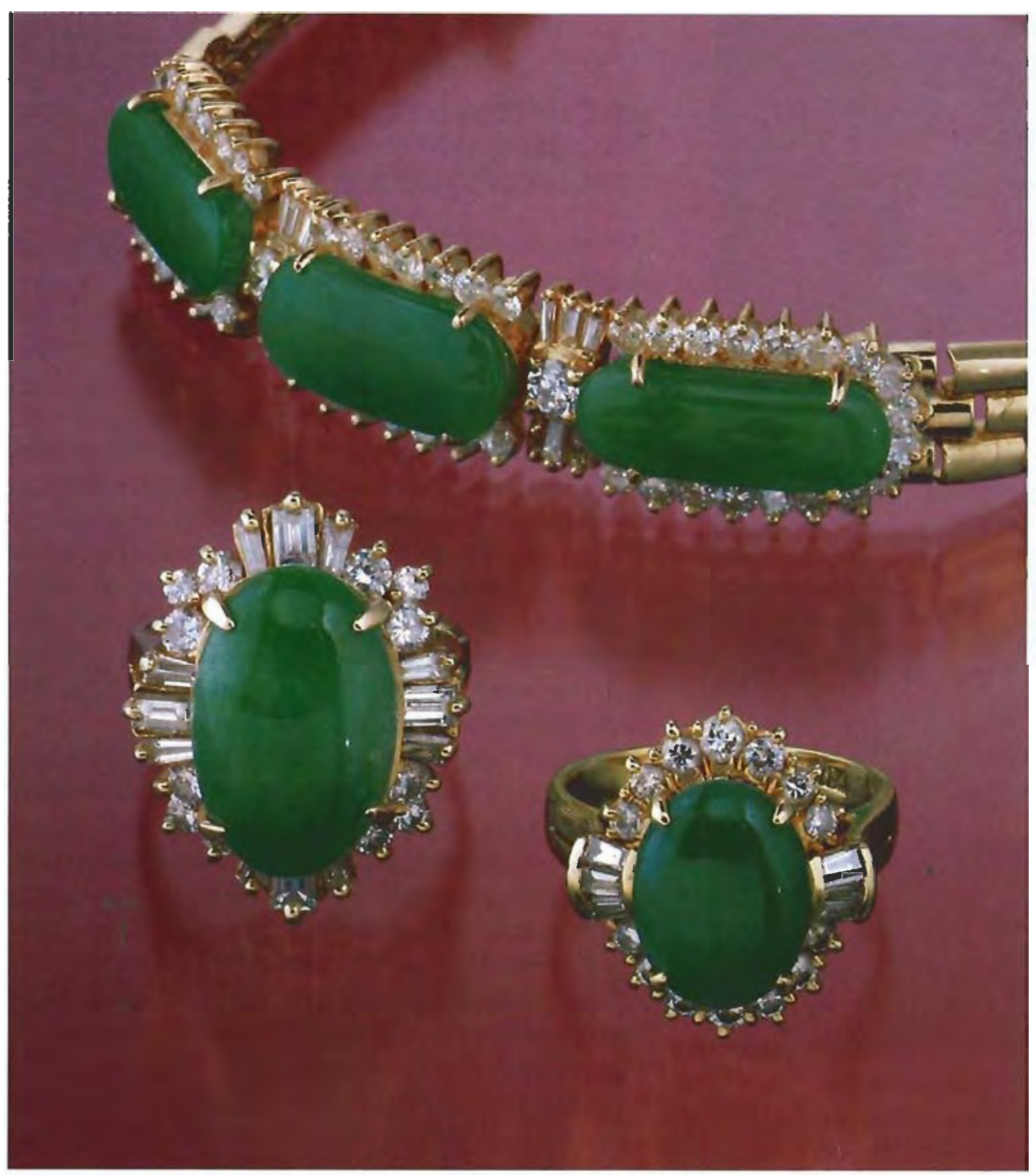

Figure 1. Jadeite that has been bleached and polymer impregnated is appearing with great frequency in the gem trade. In these attractive pieces of jadeite jade jewelry, all of the cabochons in the bracelet, as well as the cabochon in the large $(15.19 \times 10.12 \times 4.30 \mathrm{~mm})$ ring on the left, have been subjected to "bleaching" treatment, whereas the cabochon in the ring on the right has not. Photo by Shane F. McClure.

resulting voids are too visible (figure 4) and the material may be unstable.

\section{AN OVERVIEW OF JADE TREATMENTS}

Because fine jadeite is highly prized, a number of enhancements have been used. For at least 30 years, for example, most jadeite jade has been coated with a thin film of paraffin or wax to improve its luster and fill fractures and pits (Ehrmann, 1958; Crowningshield, 1972). Material that has received only a superficial waxing is often called "grade A jade" (F. Ho, pers. comm. to P. Yurkiewicz, 1991) or simply "A jade" in the trade.

Some jadeite is dyed. Green dye mixtures were reported first (see, e.g., Ehrmann, 1958), then purple and other colors (Liddicoat, 1971; Fryer, 1983). The detection of dyed green and dyed lavender jadeiteoften called " $\mathrm{C}$ jade" - is discussed in several texts (see, e.g., Koivula, 1982; Liddicoat, 1987).

The treatment discussed in this article should not be confused with another treatment, which appears to be a simple resinous coating ("Coating on jadeite," 1990; "Resinous coating reported on jadeite," 1991), that has been known for several years but reportedly is not very common in the market (Wu, 1991b). Although resins are used in the impregnation process for bleached and impregnated jade, our experiments showed that the material usually is found only at the openings of the voids or fractures, not forming a uniform coating on the surface.

On May 2, 1988, a Taiwan newspaper reported that a jadeite bangle purchased for US $\$ 400,000$ 


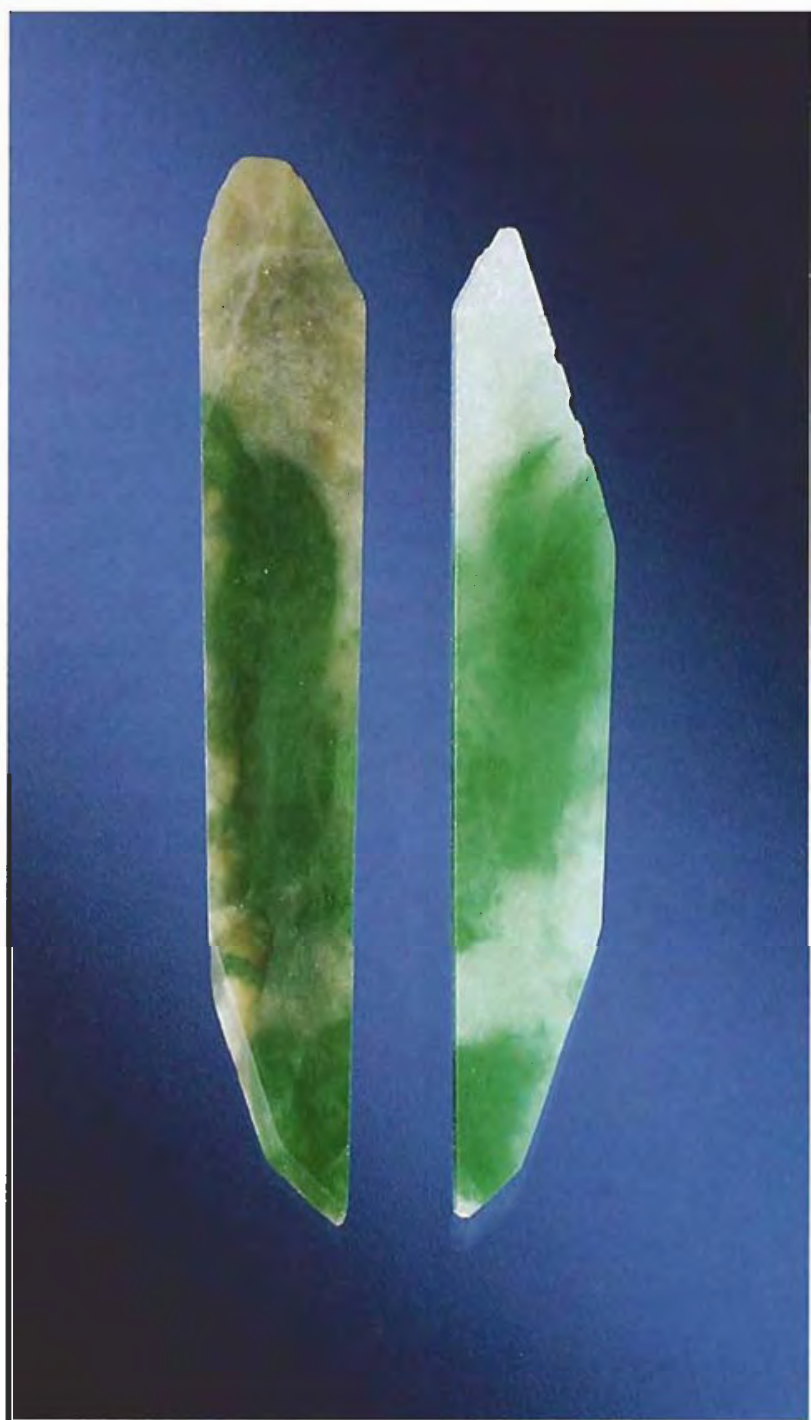

Figure 2. These two jadeite pieces, which weigh 10.32 and $7.69 \mathrm{ct}$, illustrate the effectiveness of the treatment discussed in this article. They represent two halves of the same sample, one before treatment (left) and the other after bleaching and polymer impregnation (right). Photo (C) GIA and Tino Hammid.

changed "color" (actually luster) after one month. Closer examination revealed that the bangle was jade that had been bleached and polymer impregnated (Wu, 1989). One of the authors (S-TTW) saw this type of treated jade as early as 1984. In 1989, impregnation of jadeite jade with a polymer believed at the time to be a mixture of polyacrylates was first reported in English (Hurwit, 1989). Today, significant amounts of jadeite treated in this fashion are believed to have entered the market via treatment facilities in Hong Kong and Taiwan. In the experience of one of the authors (S-TTW), as much as $90 \%$ of the jadeite sold in Taiwan has been treated in this fashion; dealers report that large amounts of this material are being sold in Hong Kong as well (e.g., D. Kay, pers. comm., 1992).

\section{DESCRIPTION OF THE BLEACHING/ POLYMER-IMPREGNATION TREATMENT PROCESS}

The first step is bleaching: The jadeite pieces, rough or fashioned, are immersed in chemicals to remove brown, iron-containing compounds present in the fractures and at grain boundaries. According to various sources (e.g., D. Mok, C. J. Ko, and F. Ho, pers. comms., 1992), hydrochloric acid is the most common bleaching agent, but nitric acid or a sodium compound may also be employed, depending on the type of jadeite and the personal experience of the treater. (One of the authors [S-TTW] observed that early treaters sometimes used the acidic juice of a sour plum from mainland China.) The jadeite is then immersed in these various chemicals for a few hours to a few weeks, depending on the porosity of the stone and the severity of the staining.

Not all jadeite responds to treatment, and treaters claim that it takes a trained eye to determine whether the treatment will be effective on a given piece. When the color appearance is deemed sufficiently improved, the jadeite is repeatedly rinsed with water. A solution of caustic soda may also be used to neutralize the acids.

If bleaching has been successful, the fractures and grain boundaries will have lost all or most of the brown coloration but will now appear as white or pale green veins (again, see figure 4) that are quite noticeable and unattractive. The bleached jadeite may also be very brittle because the material removed by bleaching leaves voids; bleached stones of the lowest quality can sometimes be completely crushed by finger pressure alone. In addition, over time, it is likely that the voids would become filled by dirt and grease-thus discoloring the stone-if subjected to normal wear in jewelry.

Therefore, bleached jadeite is typically impregnated with some kind of polymer to fill the open fractures. Occasionally, only wax is used (C. J. Ko and J. $\mathrm{Ng}$, pers. comm., 1990). In most cases, a resin is injected into the piece, reportedly under pressure ("New filler threatens jadeite sales in Japan," 1991), to replace the material lost in the bleaching process. In the experience of one of the authors (S-TTW), a vacuum pump is sometimes used to pull gas bubbles out of the fractures before they are filled. In addition, the stones may be exposed to the heat generated by a microwave oven to facilitate the injection process. Some treaters use a green dye before the impregnation or mix a dye with the impregnation material (C. J. Ko and J. Ng, pers. comm., 1990). Once impregnation is 
completed, the stones are wiped to removed any residual polymer.

\section{MATERIALS AND METHODS}

Because jadeite jade is a rock (frequently jadeite mixed with other minerals), some of its gemological properties may vary significantly from one sample to the next. It is, therefore, particularly important to study a range of samples of different color and appearance in order to ascertain that any difference in properties seen between untreated and treated samples is a consequence of the treatment, not of the natural variability of this gem material. Thus, to document the effects of this new type of jadeite treatment, we examined 42 samples of jadeite jade: 27 known to be natural and untreated, and 15 known to have been treated by "bleaching." The set of natural, untreated samples (small, approximately $1-3 \mathrm{~cm}$ ) covers a range of colors from white to dark green, with several mottled white and green. Small areas of brown or black were present on some of these samples. Eighteen of these untreated pieces were polished, in a variety of shapes, and nine were unpolished slabs. Five jadeites with lower-than-normal specific gravities were deliberately incorporated into this sample.

Among the treated pieces, four were bleached but not impregnated, two were bleached and impregnated with wax, and the remaining nine were

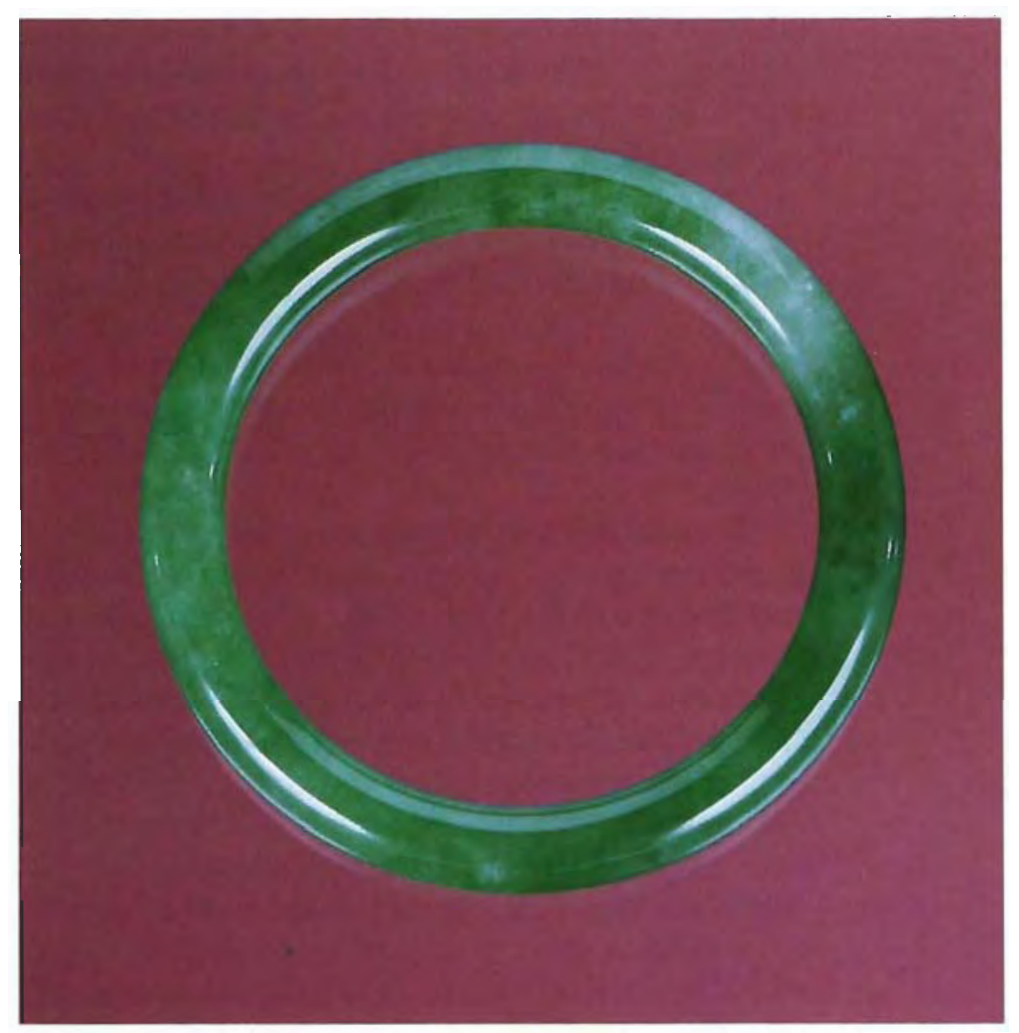

Figure 3. Virtually all qualities of jadeite are being subjected to the bleaching/polymer-impregnation treatment, including finer pieces like this bangle bracelet. Photo by Shane F. McClure.

Figure 4. The bleaching part of the treatment removes iron staining from small fractures and grain boundaries, leaving whitish or lighter color veins instead. As illustrated by the sample on the left $(1.20 \mathrm{ct})$, jadeite that has only been bleached rarely appears on the gem market because the resulting voids detract from the appearance

of the stone and may produce a "cracked" effect. Impregnation with a polymer that has a refractive index close to that of the jadeite (right, in this case wax) makes these unattractive features less prominent. Photo by Shane F. McClure.

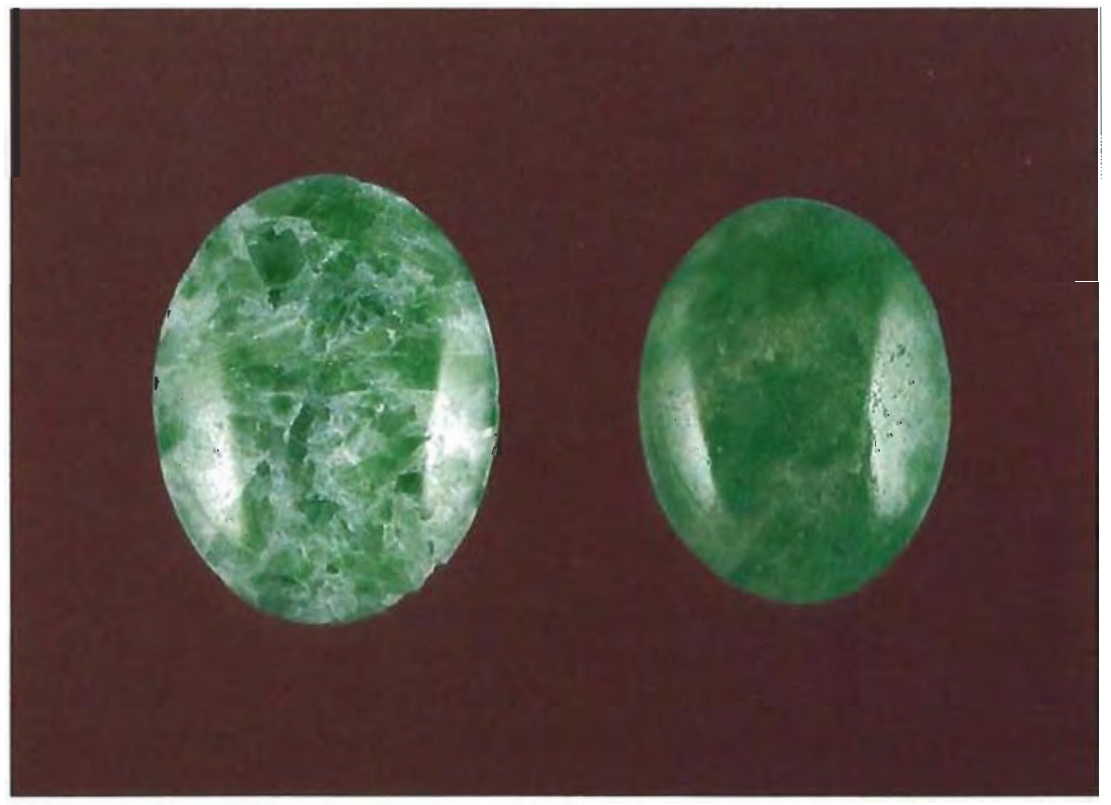


bleached and all impregnated with the same type of polymer. We also obtained four paired samples that represent the same piece of jadeite before and after treatment (see, e.g., figure 2).

We documented the gemological properties of all samples, placing particular emphasis on specific gravity, ultraviolet luminescence, thermal reaction testing, and appearance with high magnification. We used the hydrostatic method to measure specific gravity, and confirmed the results by observing the behavior of the samples in 3.32 S.G. liquid (methylene iodide).

Because infrared spectroscopy has proved useful in the detection of polymer impregnation (Amould and Poirot, 1975; Lind et al., 1983; Fritsch and Stockton, 1987; Hurwit, 1989; Shida, 1991), we recorded the infrared spectra of all samples using a Nicolet 60SX Fourier Transform Infrared (FTIR) spectrophotometer. Spectra were taken in both the mid-infrared (400 to $4900 \mathrm{~cm}^{-1}$ ) and near-infrared (3700 to 10500 $\mathrm{cm}^{-1}$ ) regions of the electromagnetic spectrum, because organic polymers are known to display strong absorptions in these regions, and these are the regions in which jadeite itself is at least partially transparent. All spectra were collected in the transmission mode, by passing the infrared beam through the jadeite sample.

To investigate potential differences in chemistry between unbleached and bleached jadeite, especially differences in iron content, we used an energy dispersive X-ray fluorescence spectrometer, the Tracor $\mathrm{X}$-ray Spectrace 5000. Because this instrument cannot detect the light elements (such as $\mathrm{C}, \mathrm{H}, \mathrm{O}, \mathrm{N}$ ) that form most polymers, we did not expect it to detect the presence of the impregnation material.

\section{GEMOLOGICAL PROPERTIES}

Index of Refraction. The index of refraction-measured by the spot method on all samples, untreated and treated, that had a polish good enough to obtain a reliable measurement (33 total) - was either 1.65 or 1.66. This is typical for jadeite jade.

Spectrum Seen with a Handheld Spectroscope. All samples showed the 437-nm line typical of jadeite, and 31 samples, both untreated and treated, showed "chromium lines" in the red.

Appearance. Most of the untreated jadeites in our sample showed the compact, polycrystalline, aggregate structure with a granular texture that is typical of jadeite (a pyroxene). A few, however, displayed more elongated crystals in a fibrous structure.
In the experience of one of the authors (S-TTW), initially only "apple green" or "flower green" material was found to be treated. Now, however, other shades of green jadeite show evidence of treatment, including the "old mine" or "imperial" color (Jade Master Stone Chart, 1981).

Because the presence of an impregnation material can often be detected by dissolving the polymer in an organic solvent, thereby noticeably reducing the luster of the material, we tested two samples of bleached/impregnated jade for their reaction to acetone. Even after total immersion for approximately 30 minutes, there was no visible change in appearance. Nor was any effect observed after immersion in alcohol for five minutes. However, other, stronger solvents might produce a different reaction.

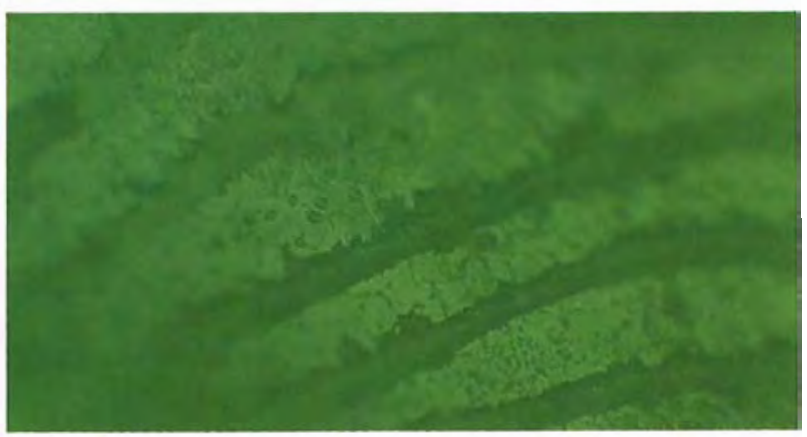

Figure 5. A drop of concentrated hydrochloric acid will produce "sweating" and beading on a natural (untreated) piece of jadeite. Photomicrograph (C) A. Hodgkinson; magnified $12 \times$.

Using information supplied by Alan Hodgkinson of Glasgow, we experimented with a new testing procedure. We placed a small drop of pure hydrochloric acid on a piece of natural (untreated) jadeite and watched for several minutes ( $\mathrm{Mr}$. Hodgkinson reports that the desired reaction will take from less than a minute to as long as 20 minutes), until we saw a "sweating" or beading of the acid at the surface of the stone, in the area immediately surrounding the droplet (figure 5). This reaction is due to capillary action in small fractures and minute spaces between the crystal grains of the jadeite. When the same test is performed on a piece of jadeite that has been bleached and polymer impregnated, no such beading or "sweating" is observed because the polymer has filled these minute spaces, thus preventing the acid 


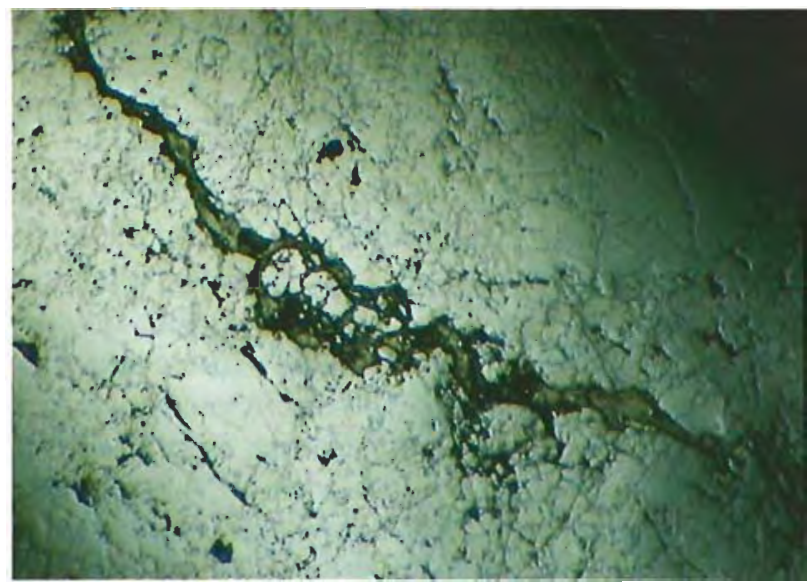

Figure 6. In reflected light, the filling material is clearly visible in this large fracture. Photomicrograph by Shane F. McClure; magnified $30 \times$.

from traveling through them. Note, however, that this test is more difficult in hot, dry areas, especially when air conditioning is used, because the $\mathrm{HCl}$ will evaporate before the desired reaction is achieved. Often the droplet will have to be replenished several times.

As noted earlier, fractures are more noticeable in samples that have been bleached but not polymer impregnated, and they may even give the overall piece a "cracked" appearance (again, see figure 4). With magnification and reflected light, the presence of a filler can be seen in some surface-reaching fractures (figure 6). Also, the poor luster typical of lowquality jadeite may be seen on some jadeite pieces, and white spots were evident on some pieces that did not respond well to treatment. In a small number of the filled fractures, we observed bubbles or lint trapped in the transparent impregnation material (figure 7). On occasion, shallow, concave "puddles" of residual impregnation material, reminiscent of those seen in some plastic-impregnated turquoises, were observed on the polished surface of a sample (R. C. Kammerling, pers. comm., 1991).

Reaction to the Thermal Reaction Tester (TRT). Four of our 27 samples of untreated jadeite showed "sweating" under the microscope near the area where the TRT was applied; subsequent infrared-spectroscopy testing (see below) showed that these four samples did, indeed, contain residual wax, which is a common final step in the polishing process in much of Asia.
The remaining untreated samples showed no reaction. The bleached-only samples did not show any reaction either, with the exception of one that displayed "sweating" near the edges of the cabochon, probably residual wax that was not removed by the bleaching treatment.

All the bleached/polymer-impregnated jades in the test sample revealed melting on contact with the TRT. This was typically accompanied by a small amount of smoke, a recognizable "plastic" odor, or a minor flow of melted material. It is important to note, however, that the impregnated jades sent through the GIA Gem Trade Laboratory generally show no reaction to the TRT. The finer-grade material that the laboratory has seen seldom has any residual polymer on the surface. The only exception is when there is a filled cavity or fracture that reaches the surface (again, see figure 6), but such features are not common in the high-quality material usually submitted to the lab.

It is also important to note that thermal-reaction testing must be performed in numerous spots on an inconspicuous area of the sample (because of the natural inhomogeneity of jadeite jade) and must be observed with a microscope. Because of the potential for damage to the stone, this test is not recommended.

Specific Gravity (S.G.). The specific gravity of natural jadeite is generally greater than 3.32 ; that is, most natural, untreated jadeites sink in the 3.32 liquid

Figure 7. We observed bubbles and lint trapped in the polymer in a small number of stones. Photomicrograph by John I. Koivula; magnified $6 \times$.

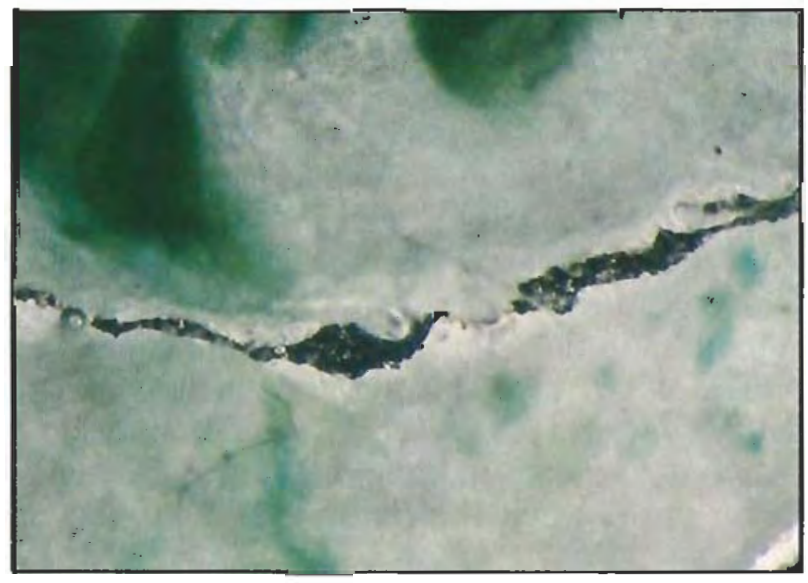




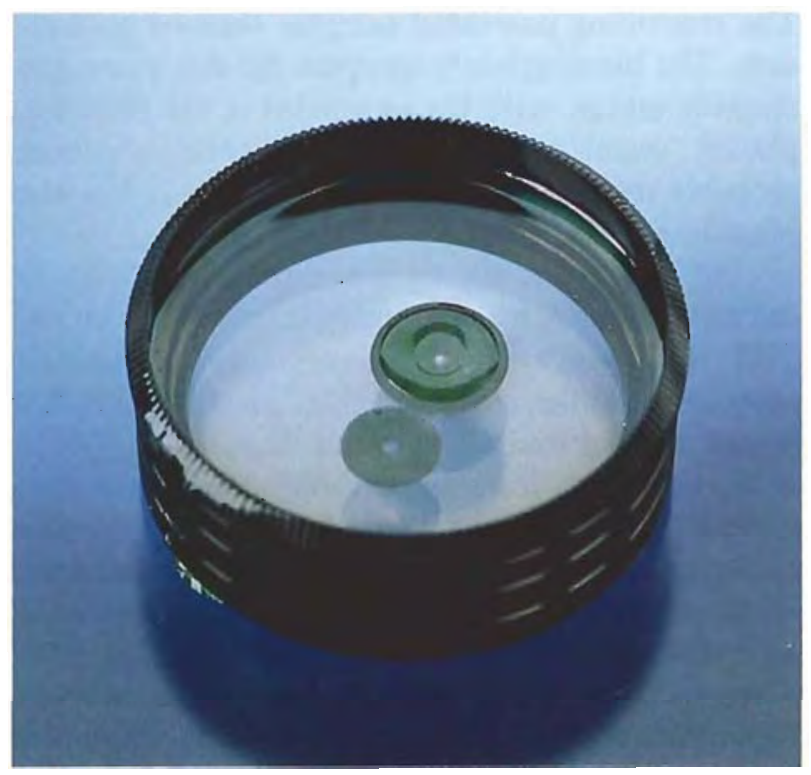

Figure 8. All of the bleached/polymer-impregnated samples in the original study floated in the 3.32 S.G. liquid. However, the authors have since examined three pieces of jadeite known to have been polymer impregnated that did not float in methylene iodide. Photo by Robert Weldon.

(Liddicoat, 1987). This was the case for 17 of our samples, with 3.44 the highest S.G. recorded.

However, some untreated, natural jadeite jades may be considerably lighter due to an admixture of amphiboles (Wu, 1991a) or feldspars (C. Fryer, pers. comm., 1992). Because we were aware of this problem, we specifically chose five low-S.G. pieces for our sample. Among the others in the sample of untreated stones, we identified an additional four with an S.G. below 3.32, and one that was only 3.15.

The specific gravities of the jadeites that had been bleached only ranged from 3.22 to 3.25 . All of the samples in our test group that had been bleached and polymer impregnated floated in the 3.32 liquid (figure 8); they ranged in S.G. from 3.04 to 3.27. This lower S.G. range is attributed to the replacement of iron compounds by relatively lighter organic polymers.

After we completed our testing of the study samples, however, we examined three pieces of jadeite submitted to the GIA Gem Trade Laboratory and proved to have been polymer impregnated that did sink very slowly in the 3.32 S.G. liquid. We believe that a polymer different from that seen in the stones in our study sample /which came from a variety of sources in Taiwan, Hong Kong, Japan, and the U.S.) was used (see "Infrared Spectroscopy" below).

Therefore, specific gravity provides a generally useful indication, but not proof, of "bleaching" treatment. In particular, a piece of jadeite that floats in 3.32 liquid (methylene iodide) should be regarded with suspicion. Such a low S.G. indicates that you may have: (1) untreated jadeite with a greater-than-normal amount of other minerals (in which case you might try to determine by careful microscopic examination if the piece contains fibrous amphiboles or other minerals that would lower the S.G. significantly, although this is difficult at best); (2) bleachedonly jadeite (not often seen in the trade); or (3) jadeite that has been bleached and polymer impregnated.

Ultraviolet Luminescence. Most natural, untreated jadeites are inert to ultraviolet radiation, as was the case with 16 of our 27 natural samples. Some fluoresced a faint to moderate yellow in white areas when exposed to long-wave U.V. radiation, with a weaker (or no) reaction to short-wave U.V. The greener areas were inert.

All of the bleached and polymer-impregnated jadeites we tested fluoresced to long-wave ultraviolet radiation and had a duller (or no) reaction to shortwave U.V.. They generally showed a faint to strong bluish white to yellowish green luminescence, which is sometimes better seen in the whitish areas of the sample. This luminescence is most likely due to the impregnation material.

Therefore, a bluish white to yellowish green luminescence to long-wave U.V. radiation provides a useful indication of treatment. However, the reaction is sometimes faint and can easily be missed. Experience also demonstrates that ultraviolet lamps from different manufacturers produce slightly different reactions, and different individuals tend to see different colors when the luminescence is weak. For these reasons, this identification criterion alone cannot be considered conclusive.

As a footnote to this section on gemological testing, we learned that a less orthodox test is being used by some dealers. Larger pieces-such as bangles or small statues - of natural, untreated jadeite have a clear ring when tapped with a coin or like object. It has been reported that similar pieces fashioned from "B jade" emit a duller, more muffled sound when the same procedure is followed. This observation has a basis in science: The polymer present in the structure of a piece will dampen the sound waves that nor- 
mally go unattenuated in untreated jadeite jade. For this unusual test to be of any significant help, though, reference samples and/or a great deal of experience with the sound emitted by both treated and untreated jade is essential. At best, this test might provide an indication of treatment and of the need for testing by the more conventional procedures described in this article. Note that this "test" is not useful with smaller pieces such as cabochons, because the treated and untreated materials will not produce noticeably different sounds.

From the preceding paragraphs, it is clear that classic gemological testing-in particular specific gravity, luminescence, and microscopic examination-can be helpful in determining whether or not a piece of jadeite is "B jade." However, none of these tests, even combined, will provide an answer in all cases. Only when the thermal reaction tester produces abundant melted wax or plastic in several areas of a sample can the piece be identified as polymer impregnated; this is not likely for most of the higher-quality treated jades that are of the greatest concern to the trade. Therefore, we proceeded to seek a method of identification with a higher degree of reliability.

\section{ADVANCED TESTING}

Energy-Dispersive X-Ray Fluorescence (EDXRF) Chemical Analysis. Because iron compounds are removed in the bleaching process, we used an analytical procedure optimized to detect iron to ascertain if the bulk iron concentration of treated samples was significantly lower than that of their untreated counterparts. We found no systematic difference in chemistry between bleached/polymer-impregnated and untreated jade. Even the two halves of the same sample, one treated and the other untreated, did not show meaningful variations. We believe that our results reflect the inhomogeneous distribution of iron in jadeite, with some of the iron dispersed in the crystal lattice (a partial cause of the green coloration in some jades), and only a portion of the brownish compounds in the cracks being close enough to the surface to be detected by EDXRF.

Infrared Spectroscopy. Untreated Jadeite. As expected, the infrared spectra of the untreated jadeite samples showed some variability, which reflects the variation in mineral composition that is typical of this rock. Most of the jadeite samples tested were opaque from 400 to about $2300 \mathrm{~cm}^{-1}$. They all showed a broad, asymmetric absorption band centered roughly between 3400 and $3550 \mathrm{~cm}^{-1}$ (figure 9a and b, black spectra). This band may be fairly smooth in shape, or it may show a number of narrow accessory peaks, for example, at 3580 or $3725 \mathrm{~cm}^{-1}$ (figure 9b, black spectrum). In eight of our 18 samples, we found two moderately sharp bands at 4320 and $4250 \mathrm{~cm}^{-1}$, which were accompanied by an absorption at $3725 \mathrm{~cm}^{-1}$ (again see figure 9b, black spectrum). In the midinfrared, almost all samples showed absorption at about $5230 \mathrm{~cm}^{-1}$ (figure 9c and d, black spectra), and six of them showed a sharp band at approximately $7295 \mathrm{~cm}^{-1}$

All of our untreated samples showed two sharp bands at approximately 2920 and $2850 \mathrm{~cm}^{-1}$, accompanied by less intense, sharp peaks at approximately 4320 and $4250 \mathrm{~cm}^{-1}$ (which were difficult to see in some of the spectra, e.g., figure 9a). The intensity of this series of bands varied widely from sample to sample, from extremely weak to-at $2920 \mathrm{~cm}^{-1}$-a peak height approximately one-quarter that of the $3400-3550 \mathrm{~cm}^{-1}$ broad band. This spectrum is due to residues of wax used after polishing, as can be seen by comparing these bands with the spectrum of a typical wax used on jadeite (figure 10). It should be noted that although all of these samples were presented to us as not having been treated, virtually all such material-rough as well as polished - is waxed before it enters the market.

Bleached-Only ladeite. All four jadeites that had only been bleached showed accessory shoulders or peaks at 3695 and $3620 \mathrm{~cm}^{-1}$ on the $3500 \mathrm{~cm}^{-1}$ broad band We observed both of these peaks in the spectra of the untreated jadeites we examined and believe, therefore, that they are unrelated to the bleaching.

Bleached and Polymer-Impregnated Jadeite. The infrared spectra of the two samples that had been bleached and wax impregnated showed little difference from the spectra of the bleached samples, only that the bands at 2920 and $2850 \mathrm{~cm}^{-1}$, which are due to wax, were very strong (again, see figure 10).

In addition to the features described for untreated and bleached jadeites, the other nine polymerimpregnated jadeites tested showed a strong absorption centered around $2900 \mathrm{~cm}^{-1}$ (again, see figure $9 \mathrm{a}$ and $\mathrm{b}$, green spectra). This absorption is composed of three sharp peaks at approximately 2965, 2930 , and $2875 \mathrm{~cm}^{-1}$. There is also a weaker, companion feature at about $3035 \mathrm{~cm}^{-1}$. 


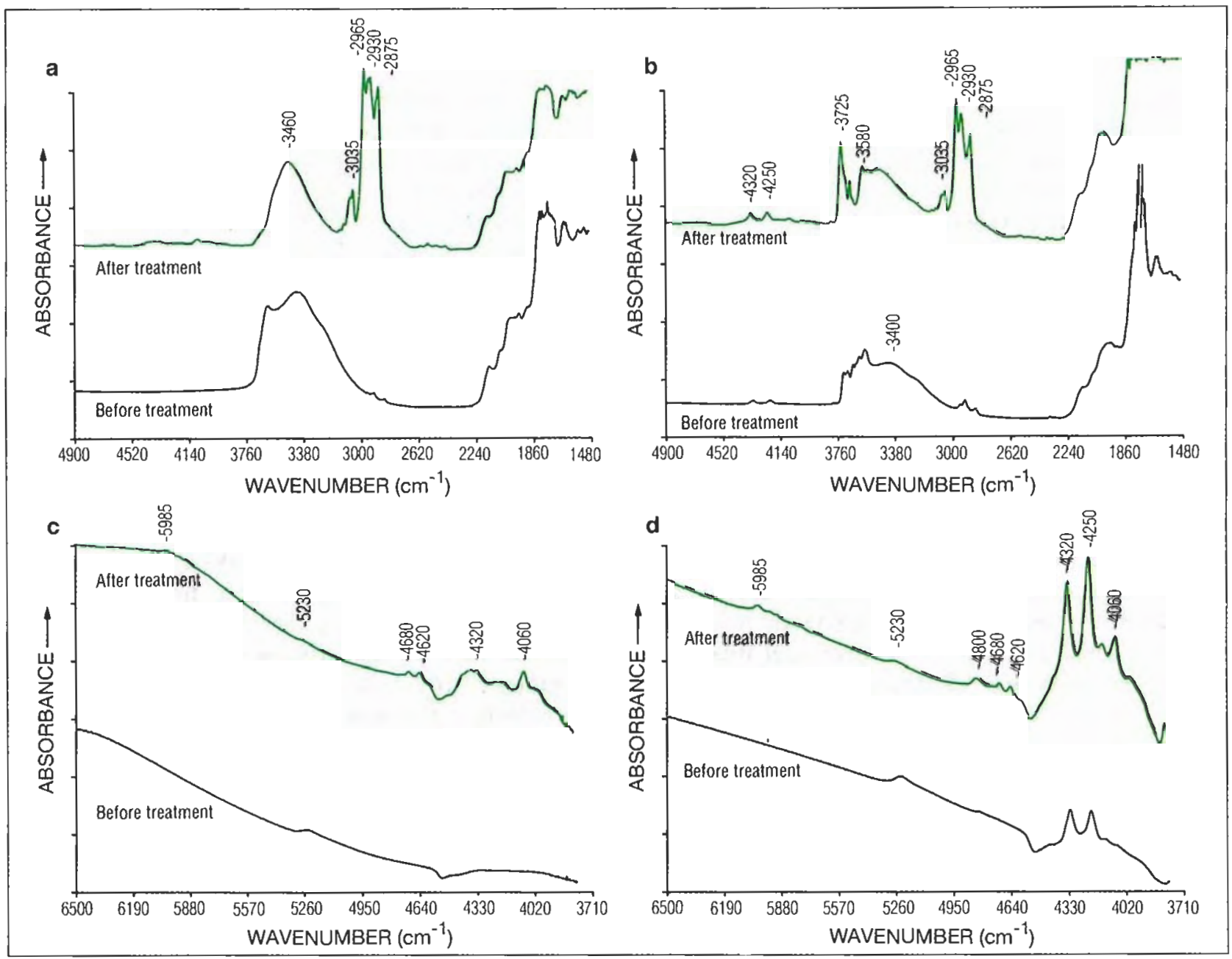

Figure 9. Shown here are the mid-infrared ( $a$ and $b$ ) and near-infrared ( $c$ and d) absorption spectra of two jadeite samples before (black) and after (green) bleaching and impregnation with a polymer. The strong absorption at about $2900 \mathrm{~cm}^{-1}$ in the mid-infrared and a series of sharp bands in the near-infrared regions of the treated specimens provide proof of polymer impregnation.

In the near-infrared, weak but sharp additional bands are seen at approximately 4060, 4620, 4680, and $5985 \mathrm{~cm}^{-1}$, the last one with some structure on its low-energy side (figure $9 \mathrm{c}$ and d, green spectra). These features are identical to those described in 1989 by Hurwit.

The pattern of infrared absorptions observed in these nine impregnated jadeites is representative of those measured for organic polymers. This spectrum is remarkably similar to that of Opticon (figure 11), a polymer commonly used in the fracture filling of emeralds and suitable for that purpose in a range of other gems (Kammerling et al., 1991). Therefore, we believe that Opticon or an Opticon-like polymer is probably used most commonly to impregnate bleached jade. The broad absorption around 3500 $\mathrm{cm}^{-1}$ is due primarily to jadeite.
We recently detected a new type of infrared spectrum in two jadeite samples (figure 12) that were not part of our study sample. These samples cannot be distinguished from other types of "B jade" on the basis of their appearance alone (figure 13). Their spectra showed a number of absorptions between 2900 and $3100 \mathrm{~cm}^{-1}$, with apparent maxima at approximately $2940,3025,3060$, and $3080 \mathrm{~cm}^{-1}$, and two broader bands at about 3440 and $3530 \mathrm{~cm}^{-1}$. This pattern corresponds exactly to the spectrum between 2800 and $3100 \mathrm{~cm}^{-1}$ of a piece of polymer given to us as one of the possible impregnation materials (again see figure 12). The best match (but not a perfect match) found in the Nicolet computer library of infrared spectra was for a family of phthalates (poly-diallyl- and diethyl-phthalates). The refractive index of this polymer is approximately 1.57, its specific gravity is about 


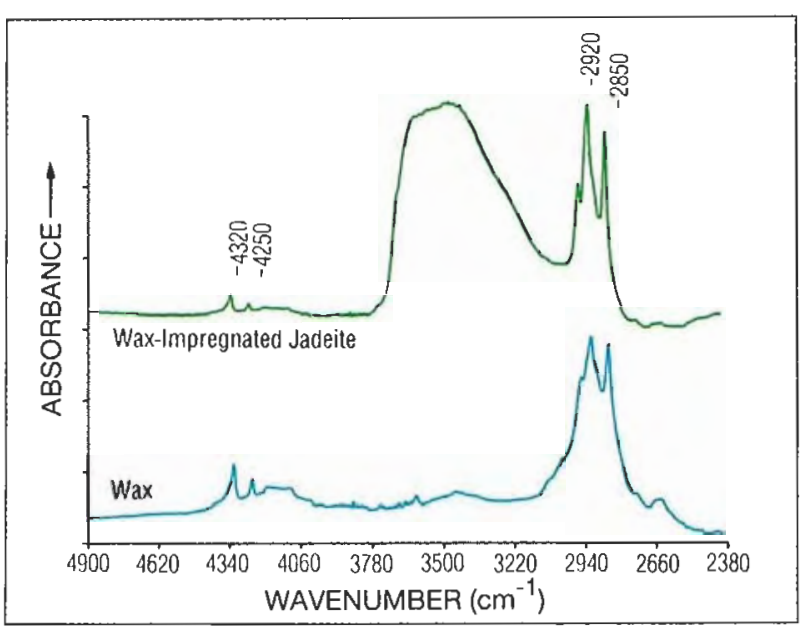

Figure 10. The mid-infrared absorption spectrum of the type of wax (bottom) commonly used to improve the luster of jadeite pieces after they are polished was seen in jadeites examined for this study that had been bleached and wax impregnated (top). In jadeites that have not been polymer impregnated, the key features are usually very weak (e.g., figure $9 a$ and $b$, black spectra).

1.20 , and it luminesces a weak bluish white to longwave ultraviolet radiation, with a weaker reaction to short-wave U.V. The two stones we studied sank very slowly in the 3.32 S.G. liquid. They luminesced a faint yellowish green to long-wave U.V. radiation and were inert to short-wave U.V.

Figure 11. These mid-infrared spectra of a typical bleached/polymer impregnated jade (middle), liquid Opticon (top), and solid Opticon (bottom) suggest that Opticon or an Opticon-like resin is often the impregnation material used.

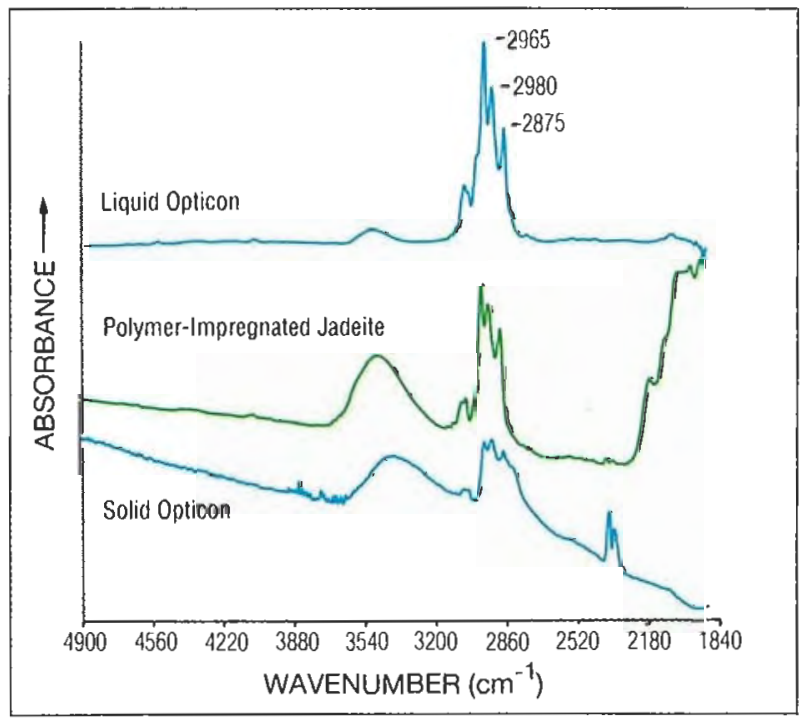

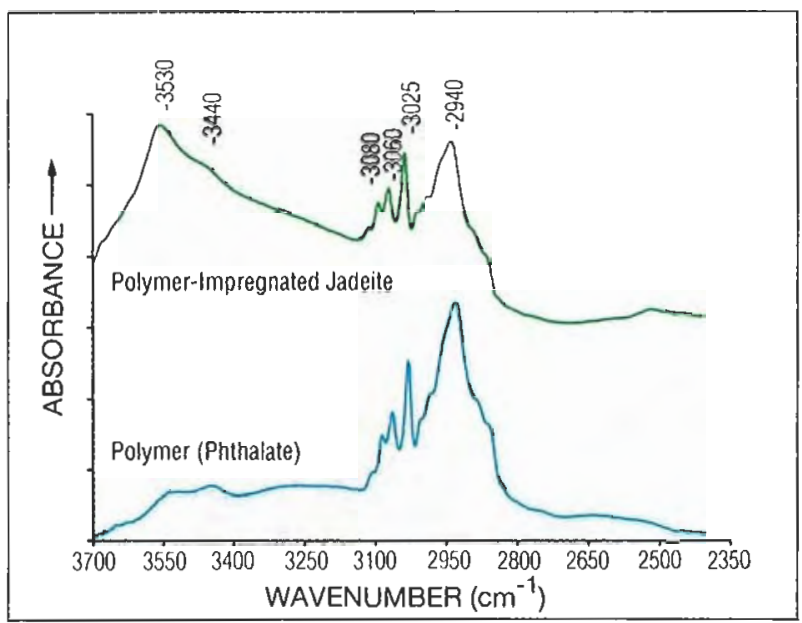

Figure 12. This mid-infrared spectrum of a new class of polymer-impregnated jadeite (top) shows absorptions significantly different from those seen in figure 9. These absorptions closely match those of a piece of polymer in the $3700-2800 \mathrm{~cm}^{-1}$ range (bottom). The best match found for this polymer was a family of phthalates.

This study demonstrates that the presence of a strong absorption around $2900 \mathrm{~cm}^{-1}$ and its accompanying features, which were seen in all of the test samples that had been bleached and impregnated, is conclusive proof of impregnation by a polymer.

The infrared spectra of the before-and-after specimens also indicate that the bleaching treatment results in a reduction of the overall absorption in the broad band centered at about $3400-3550 \mathrm{~cm}^{-1}$. Thus, we suspect that the absorption in that band might be due to some of the compounds removed by bleaching. However, because a pre-bleaching reference samples is needed to see that reduction in absorption, this technique cannot be used to detect bleaching per se for the routine testing of jadeite samples of unknown origin.

Characteristic absorptions of Opticon-like polymers can also be found in the near-infrared portion of the spectrum. This range is primarily useful when the stone is too thick to transmit in the mid-infrared, but still transmits in the near-infrared.

\section{DURABILITY OF THE "BLEACHING" TREATMENT}

Although most bleached/polymer-impregnated jades have not shown evidence of any change in appearance, durability problems have been reported with the "bleaching" treatment (Wu, 1989). In particular, after as short a period as six months to as long as a few years, pieces that had been bleached by boiling in 


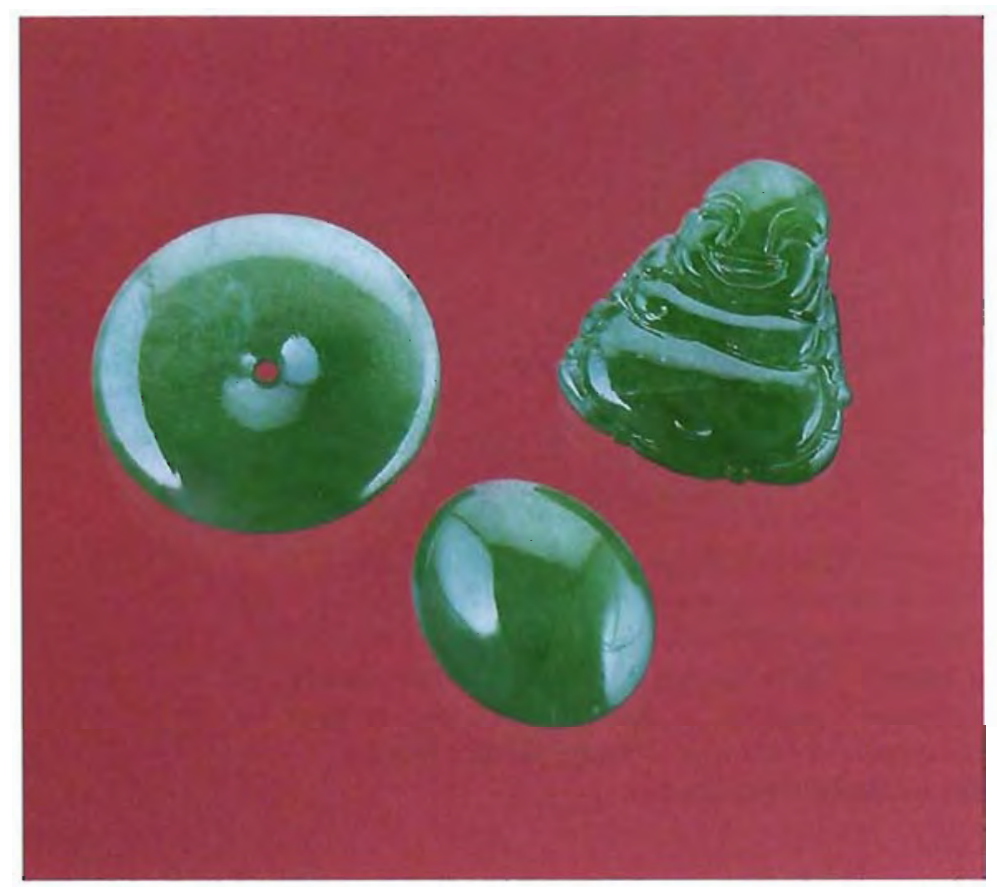

Figure 13. The use of a polymer other than one like Opticon was not evident in the visual appearance of these pieces. The spectrum shown at the top of figure 12 was taken from the carved Buddha; the other jadeites were all found to have been treated with a polymer that had a close spectral match to Opticon. Photo by Shane F. McClure.

acid have been known to exude some yellow residues of the acid treatment (C. J. Ko, pers. comm., 1990). Sometimes, in the course of normal wear, the treated jadeite will turn dark and its color will look grayer (F. Ho, pers. comm. to P. Yurkiewicz, 1991). Because most such problems are evident only after relatively long periods of time, we did not attempt to document them experimentally for this study. Note, however, that any polymer or polymer-treated product is likely to be damaged by exposure to high heat, such as that produced by a jeweler's torch. Because it appears that an Opticon-like polymer has been used in many instances, the same cautions regarding care in cleaning, setting, or repairing other Opticon-treated stones should be exercised (see, e.g., Kammerling et al., 1991\}.

\section{ATTEMPT TO MASK THE "BLEACHING" TREATMENT}

Because the purpose of the "bleaching" is to remove brown stains, most of the material that has been bleached and polymer impregnated does not show such stains. As a consequence, it is often assumed that the presence of brown stains on a piece of jadeite is proof that it has not been treated. However, one of the authors (S-TTW) recently examined a jadeite bangle that had been bleached, partly stained reddish brown, and then impregnated with a polymer (figure 14). Therefore, jadeite pieces that show brown staining cannot be assumed to be untreated.

\section{CONCLUSION}

Classic gemological examination is useful to identify jadeite that may have undergone bleaching and subsequent polymer impregnation. In particular, pieces that show a specific gravity below 3.32, a reaction to the thermal reaction tester, and a bluish white to yellowish green luminescence to long-wave ultraviolet radiation are likely to have been treated in this fashion. The only definitive test, however, is infrared spectroscopy: The presence of a very intense group of peaks around $2900 \mathrm{~cm}^{-1}$ and accompanying features in the mid- and near-infrared regions is characteristic of polymer impregnation. We know of three different

Figure 14. This jadeite bangle was bleached, partly dyed brown, and later impregnated with a polymer. Therefore, the presence of brown stains is not necessarily an indication that the piece is not " $B$ jade." Photo by S. T.T. Wu. 
types of polymers with slightly different spectra that are being used at this time: one is wax, another appears to be a type of phthalate, and the most common observed thus far has characteristics similar to Opticon.

In recent years, impregnation processes have been used on a variety of gem materials to enhance apparent clarity. The most prominent are diamond (Koivula et al., 1989), emerald (Kammerling et al., 1991), and now jade. The purpose of such treatments is to match the index of refraction of the impregnation material to that of the gem to be enhanced, thereby minimizing the visibility of fractures. Diamond is the most difficult material to treat in this fashion, because potential filling substances with an index of refraction of 2.4 are not plentiful. In contrast, many polymers have indices of refraction in the 1.55-1.65 range, close to the indices of beryl or jadeite.
The case of "bleached" jade also illustrates the limitations of classic gemological testing when faced with relatively sophisticated new treatments. The definitive identification of polymer impregnation, as with a growing number of identification challenges le.g., separation of inclusion-free samples of natural from synthetic ruby [Muhlmeister and Devouard, 1992] or natural from flux synthetic spinel [Muhlmeister and Fritsch, in preparation]), often requires advanced instrumentation to obtain conclusive results. These techniques are too expensive, or require too much technical expertise, to be practical for use in jewelry stores. In this sense, we have firmly entered a new era for gemology, where detection of sophisticated treatments or synthetics in many cases will require the use of expensive and technically sophisticated laboratory equipment that has no alternative in classic gemological testing.

\section{REFERENCES}

Arnould $\hat{M}_{3}^{\prime}$; Poirot J.-P. (1975) Infra-red reflection spectra of turquoise (natural and synthetic) and its substitutes. Journal of Gemmology, Vol. 14, No. 8, pp. 375-377.

Coating on jadeite (1990) Jewellery News Asia, No. 75, pp. 1, 90.

Crowningshield G.R. (1972) Paraffin ... its pros and cons. Gems (3) Gemology, Vol. 14, No. 3, pp. 84-85.

Ehrmann M.L. (1958) A new look in jade. Gems e Gemology, Vol. 9, No. 5, pp. 134-135, 158 .

Fritsch E., Stockton C.M. (1987) Infrared spectroscopy in gem identification. Gems e) Gemology, Vol. 23, No. 1, pp. 18-26

Fryer C.W., Ed. \{1983\} Gem trade lab notes: Jade, dyed blue jadeite. Gems $\Theta$ Gemology, Vol. 19, No. 2, p. 115.

Green jadeite bleached then dyed emerald green (1991) Jewellery News Asia, No. 79, pp. 122, 124.

Hurwit K. (1989) Gem trade lab notes: Impregnated jadeite jade. Gems e Gemology, Vol. 25, No. 4, pp. 239-240.

lade Master Stone Chart, 2nd ed. (1981) Jade N'Gem Corp. of California, Los Angeles.

Kammerling R.C., Koivula J.I., Kane R.E., Maddison P., Shigley J.E., Fritsch E. (1991) Fracture filling of emeralds: Opticon and traditional oils. Gems ev Gemology, Vol. 27, No. 2, pp. $70-85$.

Koivula J.I. (1982) Some observations on the treatment of lavender jadeite. Gems $@$ Gemology, Vol. 18, No. 1, pp. 32-35.

Koivula J.I., Kammerling R.C., Fritsch E., Fryer C.W., Hargett D., Kane R.E. (1989) The characteristics and identification of filled diamonds. Gems e Gemology, Vol. 25, No. 2, pp. 68-83

Liddicoat R.T. Jr. (1971) Dyed light-violet jade. Gems es Gemology,
Vol. 13, No. 10, pp. 323-324.

Liddicoat R.T. Jr. (1987) Handbook of Gem identification, 12th ed. Gemological lnstitute of America, Santa Monica, CA.

Lind T., Schmetzer K., Bank H. (1983) The identification of turquoise by infrared spectroscopy and X-ray powder diffraction. Gems « Gemology, Vol. 19, No. 3, pp. 164-168.

Muhlmeister S., Devouard B. (1992) Determining the natural or synthetic origin of rubies using energy-dispersive X-ray fluorescence (EDXRF). In Alice S. Keller, Ed., Proceedings of the International Gemological Symposium 1992, Gemological Institute of America, Santa Monica, CA, pp. 139-140.

Muhlmeister S., Fritsch E. (in preparation) Energy-dispersive Xray fluorescence and its application to the separation of natural from synthetic flux-grown red spinels.

New filler threatens jadeite sales in Japan (1991) Jewellery News Asia, No. 82, pp. 1, 72 .

Resinous coating reported on jadeite (1991) ICA Gazette, February, p. 9.

Shida J. (1991) Treated jadeite. Proceedings of the XXIII International Gemmological Conference, Stellenbosch, South Africa, 5-18 October 1991

Wu S.-T.T. (1989) Of the gemological aspects of jadeite jade (in Chinesel. Jewelry Circle's, Vol. 12, pp. 74-79.

Wu S.-T.T. (1991a) Research on identified black jade (in Chinese). JeweIry Circle's, Vol. 19, pp. 83-84.

Wu S.-T.T. (1991b) How to identify the new jadeite imitations (in Chinese). Jewelry Journal, No. 2, pp. 6-8. 